\title{
Excretion of 1,2,4-benzenetriol in the urine of workers exposed to benzene
}

\author{
O INOUE, ${ }^{2}$ K SEIJI, $^{12}$ H NAKATSUKA, ${ }^{1}$ T WATANABE, ${ }^{1}$ S-N YIN, ${ }^{3}$ G-L LI, ${ }^{3}$ \\ S-X CAI,$^{3} \mathrm{C} \mathrm{JIN}^{3}{ }^{3} \mathrm{M} \mathrm{IKEDA}^{1}$ \\ From the Department of Environmental Health, ${ }^{1}$ Tohoku University School of Medicine, and Center of \\ Occupational Medicine, ${ }^{2}$ Tohoku Rosai Hospital, Sendai 980 Japan, and Institute of Occupational Medicine, ${ }^{3}$ \\ Chinese Academy of Preventive Medicine, Beijing, China
}

\begin{abstract}
Urine samples were collected from 152 workers (64 men, 88 women) who had been exposed to benzene, 53 workers (men only) exposed to a mixture of benzene and toluene, and 213 non-exposed controls (113 men, 100 women). The samples were analysed for 1,2,4-benzenetriol (a minor metabolite of benzene) by high performance liquid chromatography. The time weighted average solvent exposure of each worker was monitored by diffusive sampling technique. The urinary concentration of 1,2,4-benzentriol related linearly to the intensity of exposure to benzene both in men and women among workers exposed to benzene, and was suppressed by toluene co-exposure among male workers exposed to a mixture of benzene and toluene. A cross sectional balance study in men at the end of the shift of a workday showed that only $0.47 \%$ of benzene absorbed will be excreted into urine as 1,2,4-benzenetriol, in close agreement with previous results in rabbits fed benzene. The concentration of 1,2,4-benzenetriol in urine was more closely related to the concentration of quinol than that of catechol. The fact that phenol and quinol, but not catechol, are precursors of $1,2,4-$ benzenetriol in urine was further confirmed by the intraperitoneal injection of the three phenolic compounds to rats followed by urine analysis for 1,2,4-benzenetriol.
\end{abstract}

\section{1,2,4-Benzenetriol (1,2,4-trihydroxybenzene, or} hydroxyquinol) was identified as a minor urinary metabolite after administration of benzene to rabbits by mouth,' and catechol has been assumed to be a precursor of this compound. 'Although Greenlee et al proposed a high performance liquid chromatographic (HPLC) method of determination, ${ }^{2}$ no application has been attempted in occupational health, probably because the method requires a nitrogen atmosphere in analysis.

A HPLC method under aerobic conditions was developed in this laboratory and successfully applied to measure 1,2,4-benzenetriol in the urine of workers exposed to benzene. In addition, an experiment with rats showed that 1,2,4-benzenetriol is formed from phenol through quinol (and not catechol) in vivo. The details are given in this report. Other reports on benzene metabolism in man have been published elsewhere..$^{3-6}$

Part of this work was presented at the 62nd annual meeting of the Japan Association of Industrial Health, Kanazawa, Japan, 11-14 April 1988.

Accepted 25 July 1988

\section{Material and methods}

WORKERS STUDIED, URINE COLLECTION, AND EXPOSURE MEASUREMENT

The factory survey was conducted in China in 1987. Urine samples were collected from 152 workers exposed to benzene ( 64 men, 88 women exposed up to 210 ppm benzene) and 53 workers (men only) exposed to a mixture of benzene (up to $116 \mathrm{ppm}$ ) and toluene (up to $114 \mathrm{ppm}$ ), together with 213 non-exposed controls (113 men, 100 women) (table 1) at around 1500 in the second half of a working week, when concentrations of benzene and toluene metabolites are expected to reach the maximum in the urine of workers exposed to solvents throughout a week. ${ }^{7}$ The samples from exposed workers were previously analysed for phenolic metabolites and $t$, $t$-muconic acid. ${ }^{356}$ The time weighted average exposures to solvent vapours (table 1) were measured by diffusion sampling technique, ${ }^{8-10}$ and are cited from a previous publication. ${ }^{3}$

\section{ANIMAL EXPERIMENTS}

Female Wistar rats, weighing $150-165$ g, were pur- 
Table 1 The number of workers studied and exposure intensities by group

\begin{tabular}{|c|c|c|c|c|c|c|}
\hline \multirow[b]{2}{*}{ Solvent } & \multicolumn{3}{|c|}{ No of subjects } & \multicolumn{3}{|l|}{ Exposure* } \\
\hline & Total & Men & Women & Benzene & & Toluene \\
\hline
\end{tabular}

*Arithmetic mean (unit; ppm) \pm arithmetic standard deviation (unit; ppm): maximum (unit; ppm), and (geometric mean (unit; pp伊) (geometric standard deviation)).

chased from Funabashi Farm (Funabashi, Japan). The animal room was lit from 0800 till 2000 and then kept dark till 0800 next morning. In the experiment the rats (9-10 animals per group) were individually housed in metabolic cages and given $50 \mathrm{mg} / \mathrm{kg}$ phenol, quinol or catechol in saline intraperitoneally - that is, one third to a quarter the $\mathrm{LD}_{50}{ }^{11}$-at 0930 . Urine excreted thereafter was collected separately from faeces for three four hour periods and then one 12 hour period till 0930 next morning. At each sampling, the urine was combined with the wash of the funnel in the bottom of the cage to a volume of $10 \mathrm{ml}$ in cases of four hour collections or $30 \mathrm{ml}$ when collection was made for a 12 hour period.

\section{ANALYSIS OF URINE FOR BENZENE METABOLITES} The methods for determination of catechol and quin$o l,{ }^{5}$ and $t, t$-muconic acid ${ }^{6}$ have been described previously. To determine 1,2,4-benzenetriol, an aliquot $(0.5 \mathrm{ml})$ of the urine sample (diluted when necessary) was taken in a screw capped glass tube, acidified by the addition of $0.05 \mathrm{ml}$ of $35 \%$ hydrochloric acid, and then successively mixed with $0.5 \mathrm{ml}$ of $2 \%$ pyrogallol in methanol and $0.1 \mathrm{ml}$ of $35 \%$ hydrochloric acid. The tube was sealed and heated at $100^{\circ} \mathrm{C}$ for 60 minutes for hydrolysis. The hydrolyzate was kept in the dark overnight and then spun at $\mathbf{3 0 0 0}$ $\mathrm{rpm}$ in a clinical centrifuge. A portion $(20-40 \mu \mathrm{l}$ per injection) of the supernate was introduced into a high performance liquid chromatograph (HPLC; Hitachi Model 635) equipped with a Spherisorb ODS $5 \mu \mathrm{m}$ column $(4 \mathrm{~mm}$ in inner diameter and $250 \mathrm{~mm}$ in length). A mobile phase (a mixture of methanol/water/ acetic acid at the ratio of $20 / 971 / 9$ by volume) was allowed to flow at a rate of $1.1 \mathrm{ml} / \mathrm{min}$ and the eluate was monitored at a wavelength of $290 \mathrm{~nm}$. Under the conditions established, a nitrogen atmosphere ${ }^{2}$ is not necessary, whereas keeping the hydrolyzate overnight in the dark apparently improves the reproducibility of the measurement. In a preliminary experiment a urine sample from a worker exposed to benzene containing about $30 \mathrm{mg}$ endogenous 1,2,4-benzenetriol $/ \mathrm{ml}$ was divided into 20 portions, of which 10 were analysed immediately after hydrolysis and the remaining 10 after standing overnight in the dark. The coefficient of variation was $7.0 \%$ in the former and $2.3 \%$ in the latter. The reason for the improved reproducibility unknown. Typical chromatograms of authentic and endogenous 1,2,4-benzenetriol are shown in fig 1 , in
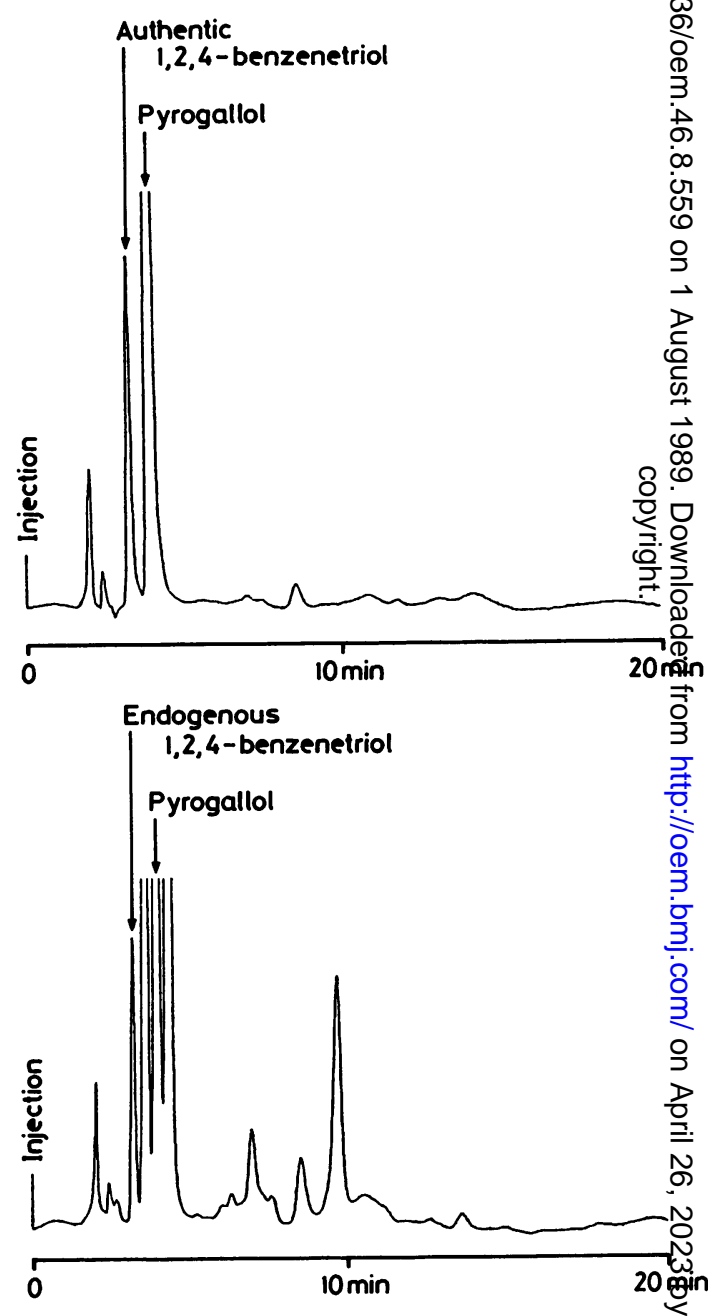

Fig 1 HPPC determination of 1,2,4-benzenetriol in urine HPLC chromatogram of authentic 1,2,4-benzenetriol dis- $\bar{\Phi}$ solved in water (top) and that of urine from a worker exposed to benzene (bottom). 
which the peak for 1,2,4-benzenetriol appeared at about $3.4 \mathrm{~min}$ after the injection with no interference with other urine components whereas the pyrogallol peak came at about $4 \cdot 1 \mathrm{~min}$.

Under the conditions of determination described above, the space in the chromatogram related linearly to the added amount of 1,2,4-benzenetriol, and the coefficient of variation was $7 \cdot 4 \%, 3 \cdot 3 \%$, and $4 \cdot 1 \%$, respectively, when urine samples containing about $5 \cdot 6$, 20.0 , and $50.0 \mathrm{mg}$ endogenous 1,2,4-benzenetriol/1 were analysed 10 times each. The recovery was $93.9 \%$ and $99.5 \%$, respectively, when 1,2,4-benzenetriol-free urine was spiked with authentic 1,2,4-benzenetriol at 50 and $100 \mathrm{mg} / 1$. The detection limit for 1,2,4benzenetriol was $0.5 \mathrm{mg} / \mathrm{l}$ urine when a space/noise ratio of 2 was taken.

The results were presented as observed (in terms of $\mathrm{mg} / \mathrm{l})$, or after correction for creatinine concentration (unit; $\mathrm{mg} / \mathrm{g}$ creatinine), ${ }^{12}$ or for a specific gravity of urine of 1.016 (unit; $\mathrm{mg} / \mathrm{l}$ ). ${ }^{13}$ The specific gravity was measured by refractometry and creatinine by colorimetry. ${ }^{14}$

\section{STATISTICAL ANALYSIS}

Regression analysis and Student's $t$-test (either paired or unpaired) were used when necessary.

\section{Results}

INCREASE IN URINARY 1,2,4-BENZENETRIOL AS A LINEAR FUNCTION OF BENZENE EXPOSURE

When the urine samples from workers (64 men, 88 women) in five benzene workshops were analysed for 1,2,4-benzenetriol and the results were classified in the increasing order of the benzene concentrations in breath zone air (table 2), the 1,2,4-benzenetriol concentrations were higher in the urine of those who were
Table 3 Correlation between benzene in breath zone and 1,2,4-benzenetriol in urine

\begin{tabular}{|c|c|c|c|c|}
\hline $\begin{array}{l}\text { Measurement } \\
\text { group }\end{array}$ & $\begin{array}{l}\text { No of } \\
\text { subjects* }\end{array}$ & $A^{\dagger}$ & $B \dagger$ & $r \ddagger$ \\
\hline $\begin{array}{l}\text { Observed value (mg/ } \\
\text { Men + women } \\
\text { Men§ } \\
\text { (Men)\| } \\
\text { Womenףा } \\
\text { Women** }\end{array}$ & $\begin{array}{l}365 \\
177 \\
(166) \\
188 \\
172\end{array}$ & $\begin{array}{c}0.182 \\
0.195 \\
(0.010) \\
0.180 \\
0.209\end{array}$ & $\begin{array}{c}0.018 \\
0.052 \\
(-0.006) \\
-0.119 \\
-0.386\end{array}$ & $\begin{array}{c}0.762 \\
0.807 \\
(0.498) \\
0.744 \\
0.672\end{array}$ \\
\hline $\begin{array}{l}\text { Value corrected for c } \\
\text { Men + women } \\
\text { Men§ } \\
\text { (Men)\| } \\
\text { Women Iा } \\
\text { Women** }\end{array}$ & $\begin{array}{l}\text { reatinine ( } \\
365 \\
177 \\
(166) \\
188 \\
172\end{array}$ & $\begin{array}{l}g / g): \\
0.212 \\
0.211 \\
(0.008) \\
0.213 \\
0.262\end{array}$ & $\begin{array}{c}0.138 \\
0.265 \\
(-0.002) \\
-0.003 \\
-0.601\end{array}$ & $\begin{array}{c}0.747 \\
0.826 \\
(0.522) \\
0.724 \\
0.678\end{array}$ \\
\hline $\begin{array}{l}\text { Value corrected for } \\
\text { Men + women } \\
\text { Men§ } \\
\text { (Men)\| } \\
\text { Women ๆ } \\
\text { Women** }\end{array}$ & $\begin{array}{c}\text { pecific gr } \\
365 \\
177 \\
(166) \\
188 \\
172\end{array}$ & $\begin{array}{c}y(\mathrm{mg} / \mathrm{l}): \\
0.148 \\
0.170 \\
(0.007) \\
0.146 \\
0.182\end{array}$ & $\begin{array}{c}0.259 \\
0.270 \\
(-0.00009) \\
0.088 \\
-0.299\end{array}$ & $\begin{array}{c}0.790 \\
0.800 \\
(0.500) \\
0.784 \\
0.749\end{array}$ \\
\hline
\end{tabular}

*Including non-exposed subjects.

tSlope (A) and the intercept on the $Y$ axis $(B)$ in the equation as $\mathbf{Y}=\mathbf{A X}+\mathbf{B}$, where $\mathbf{Y}$ is the urinary concentration of $1,2,4$ benzenetriol (unit; as described in the table) and $\mathrm{X}$ is the breath zone concentration of benzene (ppm).

$\ddagger P$ for correlation coefficient $(\mathrm{r})$ is $<\mathbf{0 . 0 1}$ for all groups.

$\S$ Exposed up to $92 \mathrm{ppm}$.

IExposed also to toluene (up to $114 \mathrm{ppm}$ ) in addition to benzene.

Iq Exposed up to $210 \mathrm{ppm}$.

**Women exposed to less than $100 \mathrm{ppm}$.

more intensively exposed, whereas the concentration was below the detection limit of $0.5 \mathrm{mg} / \mathrm{l}$ in the case of workers exposed to benzene at low concentrations, 1 ppm, for example. Further analysis of 213 urine samples from the non-exposed control subjects showed that 1,2,4-benzenetriol concentrations were essentially zero (below the detection limit) in all samples analysed.

The results from workers exposed to benzene and

Table 2 Urinary concentrations of 1,2,4-benzenetriol in workers exposed to benzene at various workshops

\begin{tabular}{|c|c|c|c|c|c|}
\hline \multirow[b]{2}{*}{ Workshop } & \multirow[b]{2}{*}{$\begin{array}{l}\text { No of } \\
\text { workers }\end{array}$} & \multirow[b]{2}{*}{$\begin{array}{l}\text { Benzene in breath } \\
\text { zone air (ppm) }\end{array}$} & \multirow[b]{2}{*}{$\begin{array}{l}\text { Observed value } \\
(\mathrm{mg} / \mathrm{l})\end{array}$} & \multicolumn{2}{|c|}{ Value corrected for } \\
\hline & & & & $\begin{array}{l}\text { Creatinine } \\
(\mathrm{mg} / \mathrm{l})\end{array}$ & $\begin{array}{l}\text { Specific gravity } \\
(\mathrm{mg} / \mathrm{l})\end{array}$ \\
\hline $\begin{array}{c}\text { Men: } \\
\text { A } \\
\text { B } \\
\text { C } \\
\text { D } \\
\text { E }\end{array}$ & $\begin{array}{c}3^{*} \\
24 \\
2^{*} \\
20 \\
15\end{array}$ & $\begin{array}{l}1,1,1 \\
11 \cdot 1(2 \cdot 40) \\
7,76 \\
32 \cdot 6 \quad(1 \cdot 42) \\
60.2 \quad(1 \cdot 28)\end{array}$ & $\begin{array}{l}\text { ND, ND, ND } \\
1.68 \quad(2.012) \\
\text { ND, } 2.9 \\
6.66 \quad(1.781) \\
11.62 \quad(2.075)\end{array}$ & $\begin{array}{l}\text { ND, ND, ND } \\
1.89(2.460) \\
\text { ND, } 5 \cdot 5 \\
9 \cdot 22 \quad(1.457) \\
13 \cdot 11 \quad(1.667)\end{array}$ & $\begin{array}{l}\text { ND, ND, ND } \\
1 \cdot 76 \quad(2 \cdot 419) \\
\text { ND, } 4 \cdot 7 \\
7.46 \quad(1.546) \\
10.37 \quad(1.649)\end{array}$ \\
\hline $\begin{array}{l}\text { Women: } \\
\text { A } \\
\text { B } \\
\text { C } \\
\text { D } \\
\text { E }\end{array}$ & $\begin{array}{c}1 * \\
19 \\
2 * \\
37 \\
29\end{array}$ & $\begin{array}{cc}1 & \\
18 \cdot 1 & (2 \cdot 79) \\
5,37 & \\
42 \cdot 4 & (2 \cdot 49) \\
76 \cdot 4 & (1 \cdot 58)\end{array}$ & $\begin{array}{l}\text { ND } \\
2 \cdot 68 \quad(3.074) \\
\text { ND, } 2.9 \\
6 \cdot 12 \quad(3.078) \\
9.60 \quad(2 \cdot 748)\end{array}$ & $\begin{array}{l}\text { ND } \\
3.02 \quad(3.365) \\
N^{2}, 4.8 \\
7.55 \quad(2.908) \\
12.85 \quad(2.445)\end{array}$ & $\begin{array}{l}\text { ND } \\
2 \cdot 46 \quad(2 \cdot 818) \\
\text { ND, } 3 \cdot 3 \\
5 \cdot 71 \quad(2 \cdot 785) \\
9 \cdot 62 \quad(2 \cdot 274)\end{array}$ \\
\hline
\end{tabular}

The results are shown in terms of geometric mean (geometric standard deviation) unless otherwise specified.

*Individual values are shown. ND = Below the detection limit of $0.5 \mathrm{mg} / 1$. 


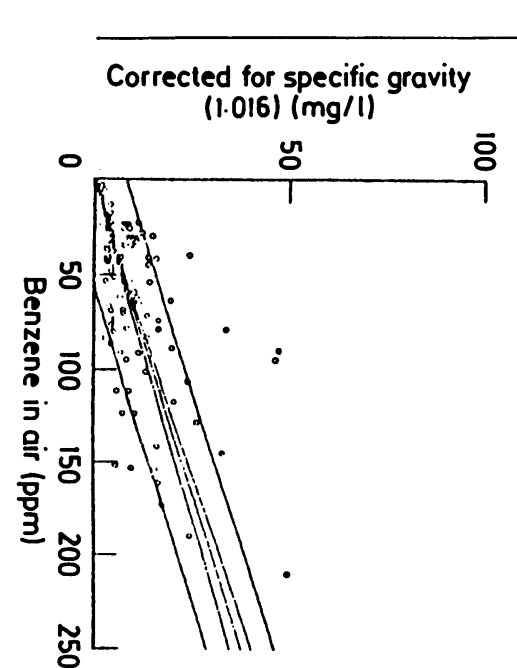

\section{$1,2,4-$ Benzenetriol in urine}

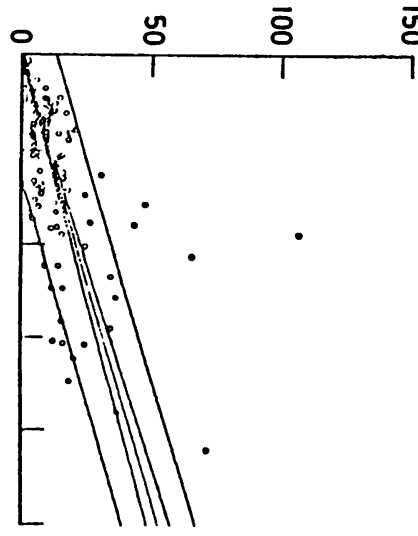

Observed value $(\mathrm{mg} / \mathrm{ll})$

$\overline{\mathrm{s}}$
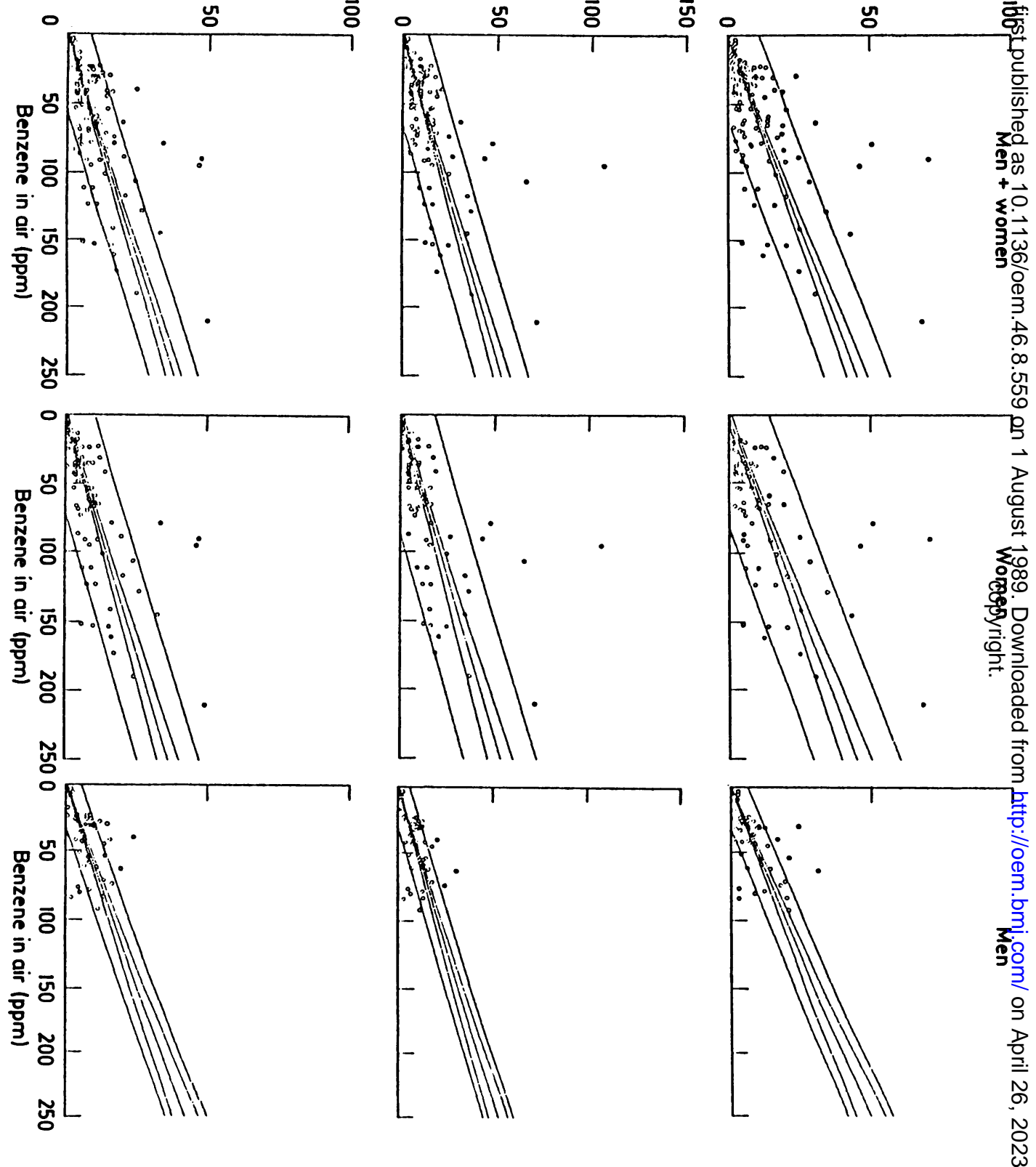

Fig 2 Relation between benzene in breath zone air and 1,2,4-benzentriol in urine. Points indicate individual values. Lines ang curves are calculated regression line (line in centre), $95 \%$ confidence ranges of sample means (curves close to regression lined and $95 \%$ confidence ranges of the individual samples (outmost lines). 
Table 4 Correlation coefficients obtained in regression analyses between 1,2,4-benzenetriol in urine as a dependent variable and benzene and toluene as two independent variables

\begin{tabular}{llll}
\hline & & \multicolumn{2}{l}{$P C C$} \\
\cline { 3 - 4 } 1,2,4-Benzenetriol & MCC & Benzene & Toluene \\
\hline As observed & 0.663 & 0.652 & -0.256 \\
$\begin{array}{l}\text { As corrected for: } \\
\text { Creatinine concentration }\end{array}$ & 0.673 & 0.660 & -0.282 \\
Specific gravity (1.016) & 0.656 & 0.642 & -0.273 \\
\hline
\end{tabular}

All the correlation coefficients in the table are statistically significant (p<0.01).

MCC = Multiple correlation coefficient.

$\mathrm{PCC}=$ Partial correlation coefficient.

controls were combined and subjected to regression analysis (fig 2). From fig 2, it was evident that a linear relation exists between the 1,2,4-benzenetriol concentration in urine (either as observed or corrected for creatinine concentration or specific gravity) and benzene concentration in breath zone air; the $95 \%$ range for a group mean was generally narrow even though the range for individual values was much wider than the group mean range. The correlation coefficient (table 3) for men and women combined was between 0.7 and 0.8 (depending on the correction for urine density, yet all being statistically significant with $p<$ 0.01 ) and the intercept on the vertical axis was next to zero. When men and women were treated separately, no pronounced sex difference was observed. As men were less intensively exposed $(<100 \mathrm{ppm})$ than women, women exposed below $100 \mathrm{ppm}$ were selected for more precise comparison between the sexes; the difference was essentially negligible (table 3 ).

\section{EFFECT OF COEXPOSED TOLUENE ON URINARY} CONCENTRATION OF 1,2,4-BENZENETRIOL

As some men were exposed to toluene in addition to benzene (the mixture group in table 1 ), the relation of the urinary 1,2,4-benzenetriol concentrations with benzene in breath zone air in the mixture group (men only) was compared with the corresponding relation in the men exposed to benzene (table 3 ). The correlation coefficients were lower in the men exposed to the mixture (around 0.5 ) than in men exposed only to benzene $(\geqslant 0 \cdot 8)$, but there was pronounced reduction in the slope; the slope was about 0.2 in the benzene group whereas it was $\leqslant 0.01$ in the mixture group. Accordingly, men in the benzene, mixture, and control groups were combined and subjected to multiple regression analysis to detect the effects of exposure to toluene separately from that of exposure to benzene. Table 4 summarises the multiple correlation coefficients (MCC) and the partial correlation coefficients (PCC) for benzene and toluene in the three cases of correction for urine density. The validity of the analysis was confirmed by the fact that MCC was statistically significant $(p<0.01)$. As expected from the simple regression analysis (table 3 , fig 2 ), the PCC for benzene was positive $(>0)$ and significant $(\mathrm{p}<$ $0.01)$. The PCC for toluene in all three cases was significantly $(\mathrm{p}<0.01)$ negative $(<0)$ even though the absolute values were small $(-0.2$ to -0.3$)$, suggesting that the urinary excretion of 1,2,4-benzenetriol due to exposure to benzene will be reduced by the coexposure to toluene in man.

QUINOL AS A PRECURSOR OF 1,2,4BENZENETRIOL

From their chemical structures, it is possible to speculate that either quinol (1, 4-benzenediol), catechol $(1,2$, -benzenediol), or both are precursors of 1,2,4-benzenetriol in vivo. When the correlation coefficient between 1,2,4-benzenetriol and quinol was compared with the coefficient between 1,2,4-benzenetriol and catechol among the workers exposed to benzene, the former value ( 0.905 for men, 0.722 for women, and 0.750 for men and women combined) tended to be larger than the latter $(0.713,0.666$, and 0.686 respectively), although the difference was statistically insignificant $(0.10<\mathrm{p}<0.15$ by paired $t$ test $)$. The observation was in favour of the hypothesis that quinol rather than catechol is a precursor of $1,2,4$ benzenetriol in man.

This possibility was further examined by an animal experiment in which rats were injected intraperitoneally with $50 \mathrm{mg} / \mathrm{kg}$ of either phenol, catechol, or quinol, and urinary excretion of 1,2,4-benzenetriol together with catechol, quinol, and $t, t$-muconic acid was followed up for 24 hours. The results are summarised in table 5. 1,2,4-Benzenetriol was found in the urine of rats given quinol, and to a lesser extent, of those given phenol, but no measurable amount was detected after injection with catechol, indicating that 1,2,4-benzenetriol is formed from phenol via quinol in vivo and that catechol will not be a precursor in 1,2,4benzenetriol formation in rats. No $t, t$-muconic acid was detected in the urine of rats given any of the three phenolic compounds (table 5). It is reasonable that a large amount of catechol or quinol was excreted in the urine of rats given catechol or quinol. The increase in excretion of quinol after injection of phenol agrees with the general belief that quinol is formed through phenol in benzene metabolism. ${ }^{15}$

\section{Discussion}

The animal experiment in the present study clearly showed that quinol is a precursor of 1,2,4-benzenetriol in rats. The observation in the urine from workers exposed to benezene that 1,2,4-benzenetriol concentrations are more closely related to the quinol concen- 
Table 5 Excretion of catechol, quinol, 1,2,4-benzenetriol, and t,t-muconic acid in the urine of rats given phenol, catechol, or quinol intraperitoneally

\begin{tabular}{|c|c|c|c|c|c|c|}
\hline \multirow{3}{*}{$\begin{array}{l}\begin{array}{l}\text { Metabolite } \\
\text { analysed }\end{array} \\
\text { 1,2,4-Benzenetriol }\end{array}$} & \multirow[b]{2}{*}{ Chemical given } & \multicolumn{5}{|l|}{ Period (h) } \\
\hline & & $0-4$ & $4-8$ & $8-12$ & $12-24$ & Total $\uparrow$ \\
\hline & $\begin{array}{l}\text { Control }(\mathbf{n}=10) \\
\text { Phenol }(n=9) \\
\text { Catechol }(n=10) \\
\text { Quinol }(n=9)\end{array}$ & $\begin{array}{l}\text { ND } \\
0.157 \pm 0.028^{*} \\
\text { ND } \\
0.531 \pm 0.141^{*}\end{array}$ & $\begin{array}{l}\text { ND } \\
0.018 \pm 0.010^{*} \\
\text { ND } \\
0.082 \pm 0.069^{*}\end{array}$ & $\begin{array}{l}\text { ND } \\
\text { ND } \\
\text { ND } \\
0.017 \pm 0.010^{*}\end{array}$ & $\begin{array}{l}\text { ND } \\
\text { ND } \\
\text { ND } \\
\text { ND }\end{array}$ & $\begin{array}{l}\text { ND } \\
0.699 \pm 0.108 \frac{\bar{O}}{\bar{\sigma}} \\
\mathrm{ND}_{2.516} \pm 0.541 \frac{\bar{D}}{\mathrm{D}}\end{array}$ \\
\hline $\mathrm{t}, \mathrm{t}-\mathrm{Muconic}$ acid & $\begin{array}{ll}\text { Control } & (n=10) \\
\text { Phenol } & (n=9) \\
\text { Catechol }(n=10) \\
\text { Quinol }(n=9)\end{array}$ & $\begin{array}{l}\text { ND } \\
\text { ND } \\
\text { ND } \\
\text { ND }\end{array}$ & $\begin{array}{l}\text { ND } \\
\text { ND } \\
\text { ND } \\
\text { ND }\end{array}$ & $\begin{array}{l}\text { ND } \\
\text { ND } \\
\text { ND } \\
\text { ND }\end{array}$ & $\begin{array}{l}\text { ND } \\
\text { ND } \\
\text { ND } \\
\text { ND }\end{array}$ & $\begin{array}{l}\text { ND } \\
\text { ND } \\
\text { ND } \\
\text { ND }\end{array}$ \\
\hline Catechol & $\begin{array}{ll}\text { Control } & (\mathrm{n}=10) \\
\text { Phenol } & (\mathrm{n}=9) \\
\text { Catechol } & (\mathrm{n}=10) \\
\text { Quinol } & (\mathrm{n}=9)\end{array}$ & $\begin{array}{l}0.024 \pm 0.005 \\
0.045 \pm 0.009^{*} \\
2.943 \pm 0.619^{*} \\
0.049 \pm 0.012^{*}\end{array}$ & $\begin{array}{l}0.042 \pm 0.009 \\
0.049 \pm 0.015 \\
0.851 \pm 0.305^{*} \\
0.049 \pm 0.011\end{array}$ & $\begin{array}{l}0.039 \pm 0.006 \\
0.059 \pm 0.025 \\
0.363 \pm 0.143^{*} \\
0.053 \pm 0.013^{*}\end{array}$ & $\begin{array}{l}0.030 \pm 0.004 \\
0.036 \pm 0.005^{*} \\
0.030 \pm 0.008 \\
0.033 \pm 0.004\end{array}$ & $\begin{array}{r}0.781 \pm 0.065 \vec{\omega} \\
1.047 \pm 0.101 \text { } \\
16.986 \pm 2.2980 \\
0.998 \pm 0.073 \frac{D}{3}\end{array}$ \\
\hline Quinol & $\begin{array}{ll}\text { Control } & (n=10) \\
\text { Phenol } & (n=9) \\
\text { Catechol } & (n=10) \\
\text { Quinol } & (n=9)\end{array}$ & $\begin{array}{l}0.013 \pm 0.004 \\
0.383 \pm 0.074^{*} \\
0.041 \pm 0.019^{*} \\
3.483 \pm 0.555^{*}\end{array}$ & $\begin{array}{l}0.028 \pm 0.008 \\
0.156 \pm 0.072^{*} \\
0.027 \pm 0.009 \\
0.605 \pm 0.391^{*}\end{array}$ & $\begin{array}{l}0.024 \pm 0.003 \\
0.044 \pm 0.020 \\
0.031 \pm 0.013 \\
0.109 \pm 0.029\end{array}$ & $\begin{array}{l}0.023 \pm 0.003 \\
0.028 \pm 0.005 \\
0.029 \pm 0.029 \\
0.043 \pm 0.015^{*}\end{array}$ & $\begin{array}{r}0.540 \pm 0.043 \\
2.660 \pm 0.443 \\
0.839 \pm 0.3410 \\
17.299 \pm 2.1640\end{array}$ \\
\hline
\end{tabular}

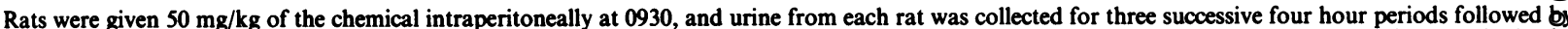

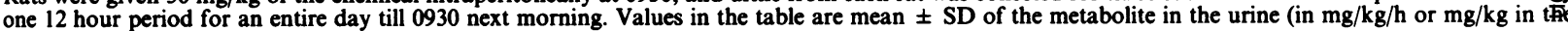
case of the total).

ND means below the detection limit which is $<0.001 \mathrm{mg} / \mathrm{kg} / \mathrm{h}$ or $0.02 \mathrm{mg} / \mathrm{kg} / 24 \mathrm{~h}$ for the four metabolites analysed.

*Indicates a statistically significant difference from the corresponding control ( $\mathrm{p}<0.01$ by unpaired $t$ test).

$+A$ total of the amount excreted in the 24 hour period.

trations than to the catechol concentrations agrees with the finding in the animal experiment and suggests that 1,2,4-benzenetriol is probably formed via phenol through quinol in workers exposed to benzene.

Assuming, as in previous studies, ${ }^{356}$ that the absorption rate of benzene through the lungs is $50 \%$ and that the respiration rate is $15 \mathrm{l} / \mathrm{min}$, a worker exposed to benzene at $100 \mathrm{ppm}$ will absorb $2392.5 \mu \mathrm{g} / \mathrm{min}$. With an additional assumption that the rate of excretion of urine is $1 \mathrm{ml} / \mathrm{min},{ }^{356}$ the amount of benzene excreted in urine in the form of 1,2,4-benzenetriol after one day's exposure to benzene at $100 \mathrm{ppm}$ (table 3) will be $0.182 \times 100(\mathrm{mg} / \mathrm{l}) \times 1 \times 10^{-3}(1 / \mathrm{min})=18.2 \mu \mathrm{g} / \mathrm{min}$ or $11.27 \mu \mathrm{g} / \mathrm{min}$ as benzene $(=18.2 \mu \mathrm{g} / \mathrm{min} \times 78.11 /$ 126.11), where $78 \cdot 11$ and $126 \cdot 11$ are the molecular weight of benzene and 1,2,4-benzenetriol, respectively. In other words, about $0.47 \%(=11.27 / 2392.5)$ of benzene absorbed will be excreted into the urine as 1,2,4-benzenetriol at the end of a shift of a workday. Results of similar calculations for phenol, catechol, quinol, and $t, t-m u c o n i c$ acid are summarised, with the present result, in table 6 and compared with the observation after oral administration of benzene to rabbits. ${ }^{1}$ There is pronounced similarity between the results from an animal feeding study ${ }^{1}$ and urine analysis after occupational exposure. ${ }^{356}$ The observation that phenol and less quinol were excreted in rabbits as compared with man will be understandable when the fact that a large amount of benzene (0.4-0.5 $\mathrm{g} / \mathrm{kg}$ ) was given by gavage at one time to rabbits is taken into account; the pathway from phenol to quinol may be temporarily saturated by massive formation of phenol, leading to relatively less formation of quinol and therefore 1,2,4-benzenetriol.

From the view point of biological monitoring of exposure to benzene by means of urine analysis, 1,2,4benzenetriol has an advantage in that the level is zero in non-exposed subjects and there is no "background level"; monitoring low level exposure by phenol, catechol, quinol, and $\mathrm{t}, \mathrm{t}$-muconic acid is complicated by the presence of the target chemical in the urine of non-exposed subjects. ${ }^{356}$ The complexity of the preHPLC treatment necessary for the analysis of 1,2,4benzenetriol contrasts with the simple procedure for $t$, $\mathrm{t}$-muconic acid determination, ${ }^{6}$ but the greatest dis-

Table 6 Comparison of benzene metabolism in man and rabbit

\begin{tabular}{lcr}
\hline Urinary metabolite & Man $^{*}$ & Rabbit \\
\hline Phenol & $13.2 \% \ddagger$ & $23.5 \%$ \\
Catechol & $1.6 \% \$$ & $2.2 \%$ \\
Quinol & $10.2 \% \S$ & $4 \cdot 8 \%$ \\
$1,2,4-$ Benzenetriol & $0.5 \% \|$ & $0.3 \%$ \\
t,t-Muconic acid & $1.9 \%$ ๆ & $1 \cdot 3 \%$ \\
\hline
\end{tabular}

*The estimate for the end shift urine from a worker exposed to benzene at $100 \mathrm{ppm}$ as a time weighted average.

tThe observation in the urine of a rabbit after oral administration of $0.4-0.5 \mathrm{~g} / \mathrm{kg}$ of benzene. Values are cited from Williams.

$\ddagger$ Value cited from Inoue et $\mathrm{al}^{3}{ }^{3}$

$\S$ Values cited from Inoue et al. ${ }^{\text {s }}$

IIThe recent study.

Iๆ Value cited from Inoue et al. ${ }^{6}$ 
advantage of the method is the suppressive effect of toluene, since the coexistence of this solvent is likely in various workplaces. ${ }^{16} 17$ This is the problem common to monitoring exposure to benzene by urine analysis for metabolites (with the possible exception of cate$\mathrm{chol}^{\mathrm{s}}$ ), and must be taken into account. In this connection, it should be noted that both benzene and toluene can be analysed simultaneously either by grab sampling or by diffusive sampling ${ }^{89}$ as long as gaschromatography is used.

We thank the Health Bureau of Hefei City and Dr S-L Fu, Ms R-G Zhang, Mr W-G Wu, Ms G-F Cui, Mr LH Zai, Ms J-F Wan, Dr X-Z Wang, and Ms L-S Hong (Heifei, China) for support and cooperation during the field study. We also thank Professor T Suzuki (Tohoku Rosai Hospital, Sendai 980, Japan) for his interest in and support of this study.

\section{Requests for reprints to: Professor M Ikeda.}

\section{References}

1 Williams RT. Detoxication mechanisms. London: Chapman and Hall, 1959;188-94.

2 Greenlee WF, Chism JP, Rickert DE. A novel method for the separation and quantitation of benzene metabolites using highpressure liquid chromatography. Analyt Chem 1981;112: 367-70.

3 Inoue $\mathrm{O}$, Seiji K, Kasahara M, et al. Quantitative relation of urinary phenol levels to breathzone benzene concentrations: a factory survey. Br J Ind Med 1986;43:692-7.

4 Inoue $\mathrm{O}$, Seiji K, Watanabe K, et al. Mutual metabolic suppres- sion between benzene and toluene in man. Int Arch Occup Environ Health 1988;60:15-20.

5 Inoue $\mathrm{O}$, Seiji K, Kasahara M, et al. Determination of catechol and quinol in the urine of workers exposed to benzene. $\mathrm{Br} J$ Ind Med 1988;45:487-92.

6 Inoue $\mathrm{O}$, Seiji $\mathrm{K}$, Nakatsuka $\mathrm{H}$, et al. Urinary $\mathrm{t}$, $\mathrm{t}$-muconic acid as an indicator of exposure of workers to benzene. $\mathrm{Br} \mathrm{J}$ Ind Med 1989;46:122-7.

7 Ikeda M, Hara I. Evaluation of the exposure to organic solvents by means of urinalysis for metabolites. Sangyo Igaku 1980;22:3-17.

8 Hirayama T, Ikeda M. Applicability of activated carbon felt in the dosimetry of solvent vapor mixture. Am Ind Hyg Assoc J 1979;40:1091-6.

9 Ikeda M, Kumai M, Aksoy M. Application of carbon felt dosimetry in field studies distant from analytical laboratory. Industrial Health 1984;22:53-8.

10 Kasahara M, Ikeda M. Spontaneous desorption of organic solvents from carbon cloth. Industrial Health 1987;25:73-81.

11 National Institute for Occupational Safety and Health. Registry of toxic effects of chemical substances. 1983-84 cummulative supplement to the 1981-82 edition. Cincinnati: NIOSH, 1985. (DHHS (NIOSH) publ No 86-103.)

12 Jackson S. Creatinine in urine as an index of urinary excretion rate. Health Phys 1966;12:843-50.

13 Rainsford SG, Lloyd Davies TA. Urinary excretion of phenol by men exposed to vapour of benzene: a screening test. $\mathrm{Br} J$ Ind Med 1965;22:21-6.

14 Ikeda M, Ohtsuji H. Hippuric acid, phenol and trichloroacetic acid levels in the urine of Japanese subjects with no known exposure to organic solvents. $\mathrm{Br}$ J Ind Med 1969;26:162-4.

15 Snyder CA. Benzene. In: Snyder R, ed. Ethyl Browning's toxicity and metabolism of industrial solvents. 2nd ed. Vol 1. Hydrocarbons. Amsterdam; Elsevier, 1987:3-37.

16 Inoue $T$, Takeuchi $Y$, Hisanaga $N$, et al. A nationwide survey on organic solvent components in various solvent products. Part 1. Homogeneous products such as thinners, degreasers and reagents. Industrial Health 1983;21:175-83.

17 Kumai M, Koizumi A, Saito K, et al. A nationwide survey on organic solvent components in various solvent products. Part 2 . Heterogenous products such as paints, inks and adhesives. Industrial Health 1983;21:185-97. 